\title{
Adherence to the DASH-style Diet and the Presence of Cardiovascular Risk Factors in Adults from Tîrgu Mureș
}

\author{
Victoria Ancuța Rus',2,3, Florina Ruța2,3, Maria Sălcudean2,3, Monica Tarcea², Costela Șerban4, \\ Călin Avram¹, Iustinian Simion², Theodora Benedek ${ }^{5}$ \\ 1 Department of Informatics, University of Medicine and Pharmacy, Tîrgu Mureș, Romania \\ 2 Department of Community Nutrition and Food Hygiene, University of Medicine and Pharmacy, Tîrgu Mureș, Romania \\ 3 Romanian Nutrition and Dietetics Association \\ 4 Department of Informatics and Biostatistics, "Victor Babeș" University of Medicine and Pharmacy, Timișoara, Romania \\ ${ }^{5}$ Cardiac Critical Care Unit, Clinic of Cardiology, County Clinical Emergency Hospital, Tîrgu Mureș, Romania
}

\section{CORRESPONDENCE}

\section{Florina Ruța}

Str. Gheorghe Marinescu nr. 38

540139 Tîrgu Mureș, Romania

Tel: +40 746039863

E-mail: florinaruta24@gmail.com

\section{ARTICLE HISTORY}

Received: June 27, 2018

Accepted: July 27, 2018
Victoria Ancuța Rus • Str. Gheorghe Marinescu nr. 38 540139 Tîrgu Mureș, Romania. Tel: +40 265215551 E-mail: victoriarus91@yahoo.com

Maria Sălcudean • Str. Gheorghe Marinescu nr. 38, 540139 Tîrgu Mureș, Romania. Tel: +40 265215551 E-mail: maria.salcudean91@yahoo.ro

Monica Tarcea • Str. Gheorghe Marinescu nr. 38 540139 Tîrgu Mureș, Romania. Tel: +40 265215551 E-mail: monaumf2001@yahoo.com

Costela Șerban • Piața Eftimie Murgu nr. 2, 30004 Timisoara, Romania. Tel: +40 256204 400, E-mail: costela.serban@gmail.com

Călin Avram • Str. Gheorghe Marinescu nr. 38, 540139 Tîrgu Mureș, Romania. Tel: +40 265215 551, E-mail: avram_calin@yahoo.com

lustinian Simion • Str. Gheorghe Marinescu nr. 38, 540139 Tîrgu Mureș, Romania. Tel: +40 265215 551, E-mail: iustinian.simion@gmail.com

Theodora Benedek • Str. Gheorghe Marinescu nr. 38 540139 Tîrgu Mureș, Romania. Tel: +40 265215 551,

E-mail: theodora.benedek@gmail.com

\section{ABSTRACT}

Background: Adopting a healthy lifestyle, including a healthy diet, weight control, regular exercise, smoking cessation, and alcohol limitation, plays an important role in treating high blood pressure and cardiovascular and chronic diseases. Aim: This study aimed to investigate adherence to the DASH diet in relation to the occurrence of high blood pressure and chronic disease risk factors, in a group of people from Tîrgu Mureș. Material and methods: This was a cross-sectional study based on a food frequency and lifestyle questionnaire applied to a group of 2,010 people aged 15-92 years from Tîrgu Mureș. Results: Individuals over the age of 45 had higher DASH scores (Q4, Q5) compared to subjects younger than 40 years (Q1 and Q2, $p<0.001$ ). An important percentage (19.3\%) of subjects who preferred a meat-based diet (Q3) had significantly larger abdominal circumference (mean $92.2 \pm 0.91 \mathrm{~cm}, \mathrm{p}<0.001)$. An association between pure alcohol intake (mean $5.6 \pm 0.43 \mathrm{~g}$ ) and an unhealthy diet (Q1) was observed, compared to the average $1.7 \pm 19 \mathrm{~g}$ of alcohol consumed by subjects with a healthy diet (Q5), alcohol consumption decreasing with an increasing DASH score $(p<0.001)$. Conclusion: This study shows that individuals diagnosed with at least one cardiovascular risk factor had a higher adherence to the DASH diet than individuals with no cardiovascular risk factors, most likely due to the fact that diagnosed individuals had changed their eating behavior and lifestyle from the time of diagnosis, with a positive impact on treatment outcomes and quality of life.

Keywords: DASH diet, high blood pressure, cardiovascular risk factors, lifestyle

\section{INTRODUCTION}

Globally, nearly 18 million people die annually due to cardiovascular (CV) disease, diabetes and hypertension being the major predisposing factors and representing the direct result of the obesity epidemic that has been doubling since the 1980s. In 2014, a WHO report indicated that there were more than 1.9 billion 
overweight people in the world, and over 600 million of them were obese. According to WHO statistics, in 2008, $18.1 \%$ of the population had obesity, $40.4 \%$ had high blood pressure (HBP), and in 2012, ischemic heart disease was the main cause of death, killing 54,500 people $(21.4 \%$ of all deaths), followed by myocardial infarction (MI) with 45.4 thousand people, (17.8\% of deaths), and high blood pressure, with a mortality of $11.3 \%$ (28.8 thousand persons). ${ }^{1}$

A remarkable progress in the analysis of $\mathrm{CV}$ risk factors was achieved by the INTERHEART study, ${ }^{2}$ which assessed the importance of several cardiovascular risk factors and their association with the risk of acute myocardial infarction. Of these factors, six have been found to be significant in terms of prediction, including smoking, diabetes, high blood pressure, abdominal obesity, alcohol consumption, and low consumption of fruit and vegetables. But the most important conclusion of the above study was that the simultaneous presence of more than two risk factors explains $90 \%$ of major cardiac events, and the importance of diet and nutrition accounts for $50 \%$ of disease prevention interventions. ${ }^{2}$

The high prevalence of HBP $(60 \%)$ is a major health problem in Europe, causing approximately $25 \%$ of MIs. ${ }^{3}$ The value of blood pressure has been shown to be positively and continuously linked to the risk of developing several CV diseases, such as coronary heart disease, MI, and stroke, which can be prevented and treated. Applying therapy for HBP to risk levels below $140 / 90 \mathrm{mmHg}$ is associated with a reduction in CV complications. ${ }^{4}$

Adopting lifestyle changes, including a healthy diet, weight control, regular exercise, smoking cessation, and alcohol limitation, plays an important role in treating HBP. ${ }^{5-10}$ The DASH diet is a lifestyle approach to a healthy and balanced nutrition, developed by the National Heart Lung and Blood Institute and promoted by the American Heart Association, being recognized as a set of nutritional recommendations that was designed to help, treat, and prevent HBP. ${ }^{8-10}$ This diet recommends focusing on a lower intake of saturated fat and cholesterol to help reduce blood pressure, and promotes an increased consumption of low fat and a balanced consumption of whole grains, fish, poultry, seafood, and oilseeds. ${ }^{5}$

Therefore, it is important to assess possible associations between a DASH-style diet adherence score and chronic disease risk factors. From our knowledge, no such study has been carried out in Romania, and we proposed to investigate the adherence of the population of Tîrgu Mureș to the DASH diet in the context of the presence of cardiovascular and chronic disease factors, in order to improve compliance with the cardiovascular treatment.

\section{MATERIALS AND METHODS}

\section{Patient setting and population}

This is a cross-sectional study based on a food frequency and lifestyle questionnaire applied to a group of 2,010 people aged 15-92 years from Tîrgu Mureș. The sampling was based on the systematic method ( plying the initial cluster type in all districts of Tîrgu Mureș. Subsequently, a systematic sampling was applied, where starting from a main street, the fifth apartment building of the block or private house was chosen. For apartment buildings with 4 to 10 stories, one person from every third apartment was questioned. Data collection took place between May 2017 and July 2017, the time of the year when fruit and vegetable consumption is increased.

The interviews were conducted face to face, at the respondents' households, by trained interviewers, and had an average duration of 15 minutes, the subjects being informed of the purpose of the study, as well as the anonymity and confidentiality of their answers.

\section{Dietary assessment}

The questionnaire consisted of 106 questions related to anthropometric indicators, demographics, smoking status, lifestyle behavior, one-week food consumption estimation, and diagnosed chronic disease (ischemic cardiomyopathy, HBP, diabetes mellitus). Respondents were asked to refer to the frequency of a standard portion of a single serving over a week with 7 variants ranging from "not at all, or less than once/month" to a frequency of "2-3 times/ day". Total energy and nutrient intake was calculated by summing up energy and nutrients from all foods. We calculated the DASH score based on food and nutrients from the DASH diet, ${ }^{8,11}$ focusing on 8 food groups: high intake of fruits, vegetables, nuts and legumes, whole grains, lowfat dairy products, and low intake of sodium, red and processed meats, and sweetened beverages. ${ }^{11,12}$ For each component of the questionnaire, we calculated the number of servings per day. Then, the obtained values were divided into five quintiles, and the average values of servings per each of the five quintiles are presented in a table. Quintiles values were turned into scores, using the following criteria: for fruits, vegetables, nuts and legumes, whole grains and low-fat dairy servings $-\mathrm{Q} 1=1$ point, $\mathrm{Q} 2=2$ points, $\mathrm{Q} 3=$ 3 points, $\mathrm{Q} 4=4$ points, $\mathrm{Q} 5=5$ points; for sodium, red and processed meats, and sweetened beverages servings - Q1 $=5$ points, $\mathrm{Q} 2=4$ points, $\mathrm{Q} 3=3$ points, $\mathrm{Q} 4=4$ points, $\mathrm{Q} 5$ $=1$ point $($ Table 1$)$. We then summed up the component 
scores to obtain an overall DASH score ranging from 10 to 40. For the consumption of healthy food groups, a higher score reflected a higher consumption of those food groups. These groups were rated on a scale of 1-5; participants in quintile 5 had the highest consumption and were scored 5. Less healthy food groups, where a lower consumption is recommended, were scored using a reverse scale. Participants from quintile 1 reported the lowest consumption and scored 5. Participants from quintile 5 had the highest DASH score and a good-quality diet (Table 1).

\section{Anthropometric measurements}

Body mass index (BMI, calculated as $\mathrm{kg} / \mathrm{m}^{2}$ ) was derived from weight and height measured with a calibrated scale and a Kawe measure. Study subjects were included in the BMI classification as follows: underweight (BMI $\left.\leq 18.49 \mathrm{~kg} / \mathrm{m}^{2}\right)$, normal weight $\left(\mathrm{BMI}=18.50-24.99 \mathrm{~kg} / \mathrm{m}^{2}\right)$, overweight $\left(B M I=25.00-29.99 \mathrm{~kg} / \mathrm{m}^{2}\right)$, or obese $\left(\mathrm{BMI} \geq 30.00 \mathrm{~kg} / \mathrm{m}^{2}\right)$. Waist circumference was measured using a Kawe measuring tape, and central obesity was defined as having a waist circumference $\geq 94 \mathrm{~cm}$ for men and $\geq 80 \mathrm{~cm}$ for women. ${ }^{13}$

Blood pressure was determined using a Beurer BM 85 digital blood pressure monitor, the subject being seated, and the right arm positioned at the heart level. Participants with a systolic pressure value $\geq 140 \mathrm{mmHg}$ and a diastolic pressure $\geq 90 \mathrm{mmHg}$ were classified as hypertensive subjects.., 8

\section{Statistical analysis}

The data was collected in an Excel database, and the statistical analysis was performed using the IBM SPSS program
(Statistical Package for Social Sciences), Version 22.0 for Windows. The level of significance was considered $5 \%$, and for comparisons of ordinal variables the Mann-Whitney and Kruskal-Wallis tests were applied. Chi-squared tests were used in tables with nominal/ordinal variables. A principal component analysis (PCA) was conducted on 49 items with orthogonal rotation (varimax). The KeiserMeyer-Olkin measure verified the sampling adequacy for analysis, $\mathrm{KMO}=0.77$, which are above Keiser's criteria $(>0.5)$. Bartlett's test of sfericity $\chi 2(1176)=14716.6, p$ $<0.001$, indicated that the correlation between items was sufficiently large for PCA. An initial analysis was run to obtain eigenvalues for each component in the data. Fifteen components had eigenvalues over Keiser's criterion of 1 and in combination explained $53.7 \%$ of the variance. After inspecting the screen plot we decided to keep five components, which in combination would explain $21.5 \%$ of the variance (Table 2 ).

Table 2 shows factor loadings after rotation. The items that cluster on the same components suggest that component 1 represents a Mediterranean-like pattern, component 2 represents a pattern of consumption of meat and alcohol, component 3 represents a diet without meat, and component 4 includes fast-food eaters. Pattern 5 includes individuals who eat dairy.

The authors assert that all procedures contributing to this work comply with the ethical standards of the relevant national and institutional committees on human experimentation and with the Helsinki Declaration of 1975, as revised in 2013. This study was approved by the Scientific Ethics Committee Board at the University of Medicine and Pharmacy of Tîrgu Mureș.

TABLE 1. Dietary food group intakes according to quintiles of Dietary Approaches to Stop High Blood Pressure related to the DASH diet score

\begin{tabular}{|c|c|c|c|c|c|}
\hline \multirow[t]{2}{*}{ Components of DASH score a,b } & \multicolumn{5}{|c|}{ Quintiles DASH score } \\
\hline & $\begin{array}{c}\text { Q1 } \\
(n=432)\end{array}$ & $\begin{array}{c}Q 2 \\
(n=450)\end{array}$ & $\begin{array}{c}Q 3 \\
(n=390)\end{array}$ & $\begin{array}{c}\text { Q4 } \\
(n=391)\end{array}$ & $\begin{array}{c}\text { Q5 } \\
(n=347)\end{array}$ \\
\hline Fruitsa $^{\text {(servings/day) }}$ & 0.5746 & 0.7950 & 1.0358 & 1.2220 & 1.8153 \\
\hline Vegetablesa (servings/day) & 0.8118 & 1.1540 & 1.4017 & 1.6436 & 2.4588 \\
\hline Nuts and legumesa (servings/day) & 0.3778 & 0.4724 & 0.5780 & 0.7247 & 1.1140 \\
\hline Whole grains (servings/day) & 0.6486 & 1.4518 & 2.2074 & 2.5903 & 3.3104 \\
\hline Low-fat dairya (servings/day) & 0.1060 & 0.1862 & 0.2704 & 0.3581 & 0.4926 \\
\hline Sodiumb (mg/day) & $3,681.09$ & $2,868.23$ & $2,593.77$ & $2,225.04$ & $1,746.56$ \\
\hline Red and processed meatb (servings/day) & 1.3036 & 0.9283 & 0.7653 & 0.5367 & 0.2753 \\
\hline Sweetened beverages ${ }^{b}$ (servings/day) & 0.5915 & 0.2718 & 0.1362 & 0.0701 & 0.0262 \\
\hline
\end{tabular}

a. Scoring criteria: for fruits, vegetables, nuts and legumes, whole grains and low-fat dairy servings $-Q 1=1$ point, $Q 2=2$ points, $Q 3=3$ points, $Q 4=4$ points, $Q 5=5$ points; for sodium, red and processed meats and sweetened beverages servings - Q1 = 5 points, $Q 2=4$ points, $Q 3=3$ points, $Q 4=4$ points, $Q 5=1$ point

b. Higher quintiles represent higher intake; however, in constructing the DASH score, high intake and high quintiles received lower scores. 
TABLE 2. Diet patterns in relationship with DASH quintiles analysis - factor loadings after rotation

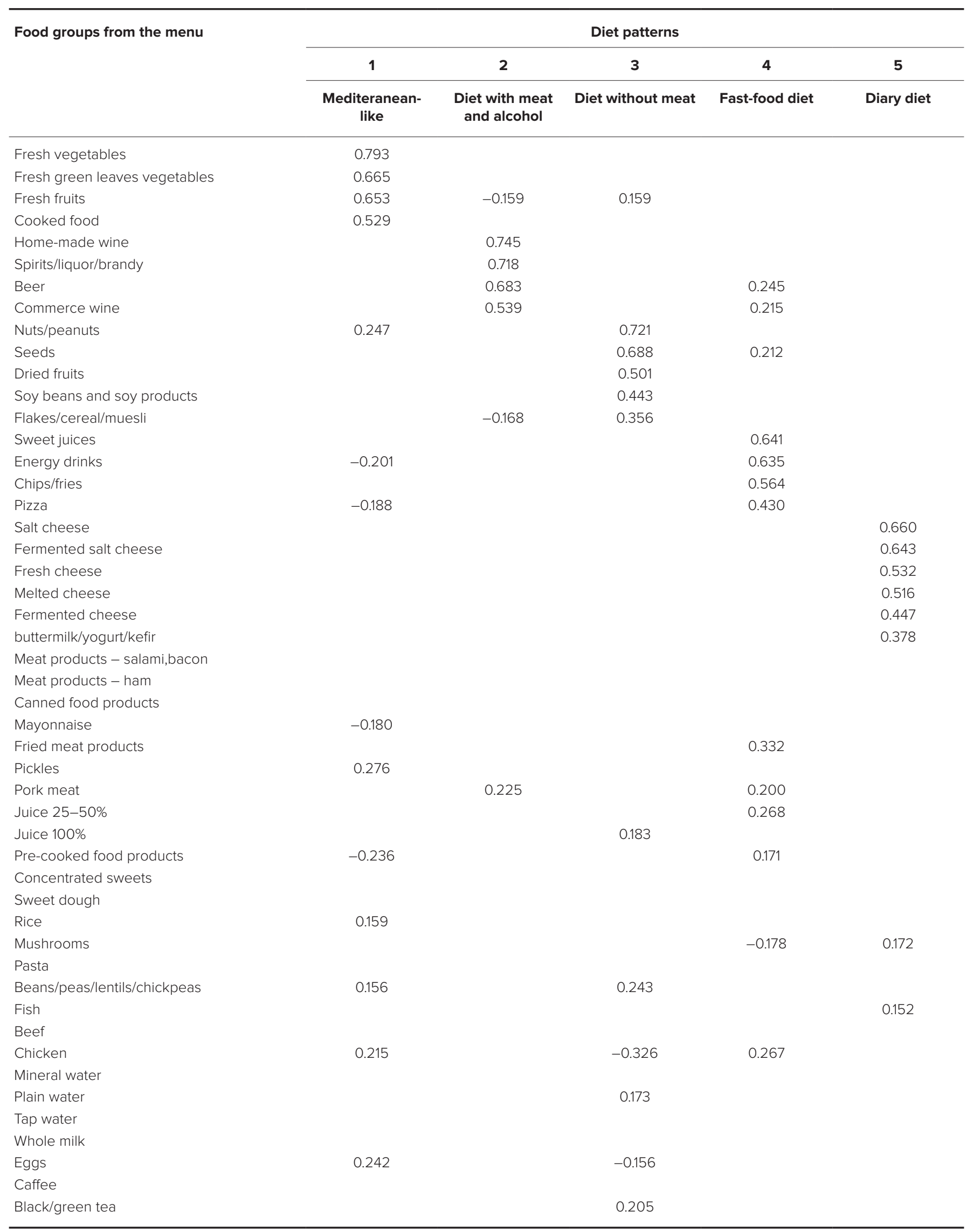


TABLE 3. Distribution of demographic characteristics and risk factors of our sample in relationship with quintiles of DASH score range

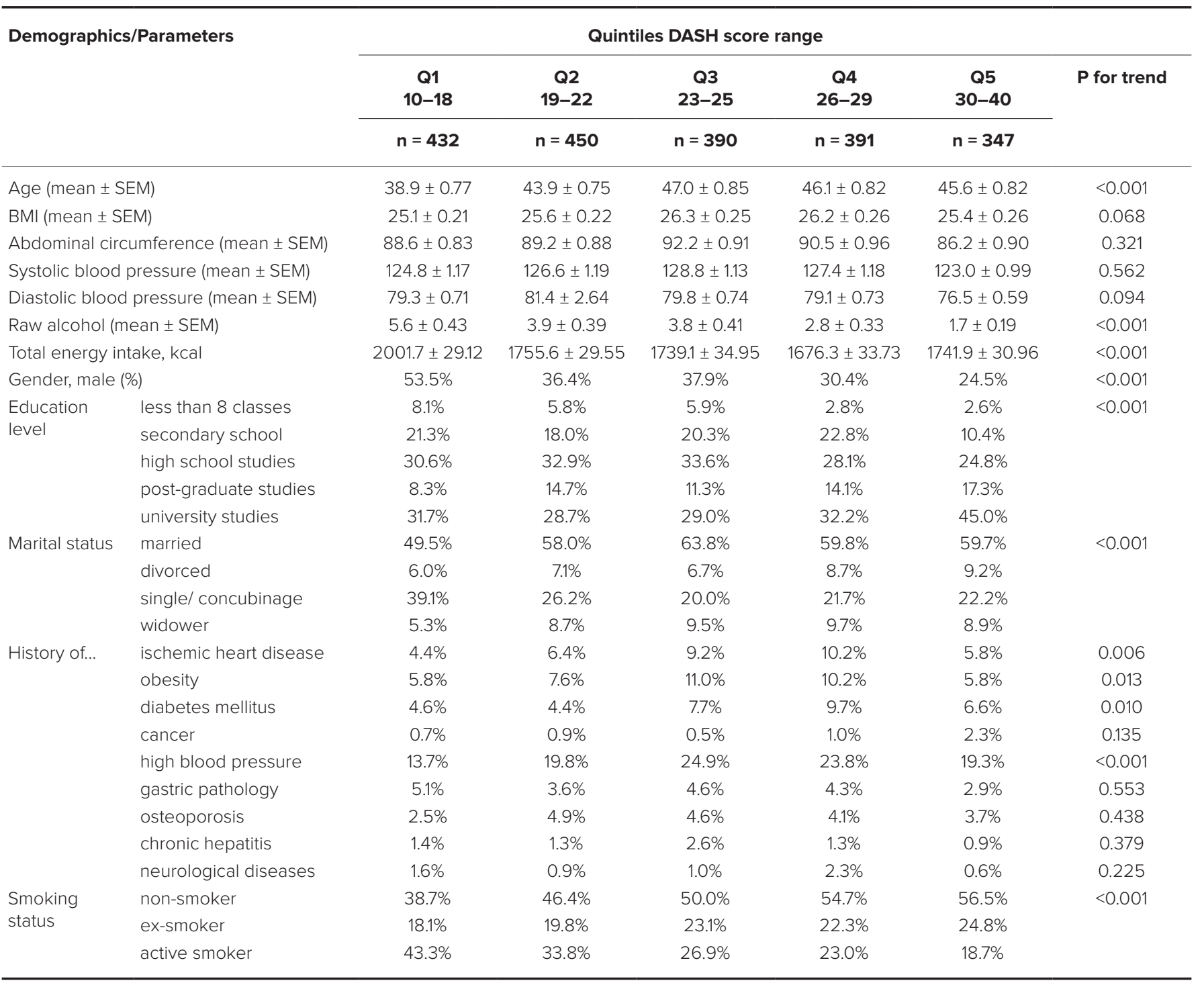

\section{RESULTS}

In the studied group, $62.8 \%(\mathrm{n}=1,263)$ of respondents were female, and the average age of the whole sample was 44.14 \pm 7.2 years (between 15 and 92 years). Almost one third of subjects have completed university studies (32.9\%), followed by $30.2 \%$ who have just completed high school.

The social-demographic characteristics of the studied group in correspondence with the DASH score quintiles are presented in Table 3. A share of $8.1 \%$ of the total respondents showed obesity, and $18.6 \%$ were overweight, the mean BMI being $25.7 \mathrm{~kg} / \mathrm{m}^{2}\left(\min =16.33 \mathrm{~kg} / \mathrm{m}^{2}\right.$, $\max$ $=54.69 \mathrm{~kg} / \mathrm{m}^{2}$ ), abdominal circumference was characterized by an average of $89.4 \mathrm{~cm}$ in both sexes $(36.5 \%$ had an abdominal circumference above the limit), and mean blood pressure was $126 / 79 \mathrm{mmHg}$ (Table 2), $20.1 \%$ of the respondents having HBP.
The study group consisted of $58.3 \%$ healthy people and $41.7 \%$ people who reported chronic illnesses, among the most common being HBP (20.1\%), ischemic heart disease (7.2\%), and diabetes mellitus (6.5\%).

Individuals over the age of 45 had higher DASH scores (Q4, Q5) than subjects under 40 years, which had Q1 and Q2, p <0.001. An important share (19.3\%) of subjects who preferred a meat-based diet (Q3) had a significantly elevated abdominal circumference $($ mean $=92.2 \pm 0.91 \mathrm{~cm}$, $\mathrm{p}<0.001)$.

An association between alcohol intake (mean $=5.6 \pm$ $0.43 \mathrm{~g}$ ) and an unhealthy diet (corresponding to DASH score $=10-18)$ was recorded; compared to the average $1.7 \pm 0.19 \mathrm{~g}$ of alcohol consumed by subjects with a healthy diet (DASH score $=30-40$ ), alcohol consumption decreased with an increasing DASH score, $\mathrm{p}<0.001$. The 


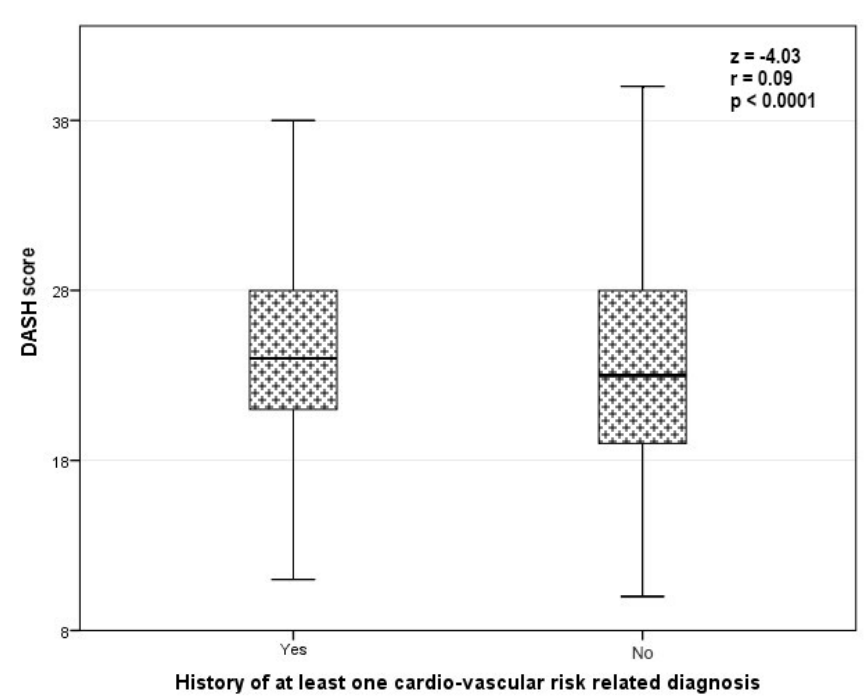

FIGURE 1. Adherence to the DASH diet style, individuals with cardiovascular risk vs. healthy individuals

highest caloric intake $(2,001.7 \pm 29.32 \mathrm{kcal})$ was found in $53.5 \%$ of male respondents with an unhealthy diet (Q1), which also explained the increased BMI (overweight and obesity).

From respondents who follow a balanced dietary intake (Q5), 45\% ( $\mathrm{p}<0.001)$ declared that they have higher education levels, and $59.7 \%$ are married custodians ( $\mathrm{p}$ $<0.001$ ). However, $63.8 \%$ of married people and $39.1 \%$ of unmarried or cohabiting relatives followed a less healthy diet (Q3). Of the non-smoker sample, 56.5\% respected a balanced diet (Q5), p <0.001, compared to smokers, of which $43.3 \%$ associated a processed food menu (Q1).

Each diet pattern was statistically associated with lifestyle and demographic risk factors when comparing data between Q5 and Q1 (Table 3).

A total of $61.9 \%$ of subjects who scored an elevated DASH score (Q5) in the Mediterranean pattern were women over the age of 47 who consume $>2,000 \mathrm{kcal} /$ day, with a DASH score of 26.2, as well as a high intake of healthy foods, vegetables, and legumes.

Patients diagnosed with at least one $\mathrm{CV}$ risk-related diagnosis had a higher median of DASH score, $\mathrm{U}=363196$, $\mathrm{z}=-4.03, \mathrm{p}<0.001, \mathrm{r}=0.09$, with a very small effect size (Figure 1), compared with healthy subjects.

\section{DISCUSSIONS}

Studies have shown that there is a link between increased chronic consumption of sodium and the occurrence of high blood pressure. ${ }^{3}$ In Europe, about $70-75 \%$ of the total salt consumed is hidden in processed food or other food prod- ucts that are not under consumer control, and the remaining $25-30 \%$ is added to meals at the table. ${ }^{3,14,15}$ While overconsumption of salt is undoubtedly a worldwide problem, there is a growing concern in the European region, where a typical diet consists of high consumption of preserved meat, bread and cheese, high-salt foods, sugar, lipids, saturated fat, and cholesterol.,16 Research has found that limiting salt intake to less than $5 \mathrm{~g} /$ day $(2,000 \mathrm{mg}$ of sodium, one teaspoon of salt) is associated with a $17 \%$ reduction in the long-term risk of developing a CV disease. ${ }^{3,17}$

The DASH diet recommends a lower intake of sodium, sugars, and fats, as well as a lower intake of saturated fat and cholesterol to help reduce blood pressure. This diet also promotes a high consumption of vegetables, fruits, and low-fat diaries, as well as a balanced intake of whole grains, cereals, fish, and legumes. ${ }^{18-21}$

According to similar studies, adherence to the DASH diet has been shown to reduce the risk of developing coronary artery disease due to limited consumption of salt and saturated fats, which prevents HBP. ${ }^{11,22,23}$

For the analyzed population from Tîrgu Mureș, the profile of the top quintiles of DASH (Q4 and Q5) was as follows: older people, who consume less alcohol, have lower or normal caloric intake, are predominantly women, graduated university, are married, non-smokers, with a significantly higher prevalence than those in the lower quintiles. Subjects from Q3 have significantly higher values for BMI, abdominal circumference, and chronic disease history than those in the extreme quintiles.

Adherence to the DASH diet has been statistically associated with the presence of chronic diseases, except for cancer. Consumption of a DASH dietary pattern was not significantly associated with the BMI or abdominal circumference. The HBP cases were associated with the consumption of lower-than-healthy food products (Q3) in a proportion of $24.9 \%$, and with a healthy lifestyle (Q5) in a share of $19.3 \%$, compared to subjects who have an increased intake of processed foods (Q1), of which only $13.7 \%$ had HBP.

In this study, increased adherence to the DASH diet was associated with age over 45 years $(\mathrm{p}<0.001)$, a BMI $>25$ $\mathrm{kg} / \mathrm{m}^{2}(\mathrm{p}<0.001)$, a lower frequency of males ( $\left.\mathrm{p}<0.001\right)$, married and non-smokers subjects $(\mathrm{p}<0.001)$, although other studies have shown that $\mathrm{CV}$ diseases are more prevalent among males. ${ }^{24}$

Lifestyle changes by community interventions that are focused on reducing the risk of $\mathrm{CV}$ diseases among the population of Tîrgu Mureș will have more effective outcomes with personalized therapy for the following risk profile: young men, smokers, and unmarried subjects, be- 
cause in these individuals we identified a low adherence to the DASH diet.

Nutritional interventions should be applied in young subjects, at school (as a primary preventive measure), but also in patients with the above-mentioned profile and registered cardiovascular risk factors (even if there is no clear diagnosis) and in patients who already have a diagnosed cardiovascular disease, in order to improve their health status.

\section{CONCLUSIONS}

This research showed that individuals diagnosed with at least one cardiovascular risk factor had a higher adherence to the DASH diet, compared to individuals with no cardiovascular risk factors, most likely because diagnosed patients have changed their eating behavior and lifestyle from the time of diagnosis, with a positive impact on treatment outcomes and quality of life. Prospective cohort studies are required to confirm these findings.

\section{CONFLICT OF INTEREST}

Nothing to declare.

\section{ACKNOWLEDGEMENT}

The present research is receiving funding from the University of Medicine and Pharmacy of Tîrgu Mureș, Romania, via governmental funds for $\mathrm{PhD}$ studies, contract number 13406/3/07.10.2015.

\section{REFERENCES}

1. Country statistics and global health estimates by WHO and UN partners. Romania: WHO statistical profile. Available at: http://www.who.int/gho/ countries/rou.pdf?ua=1.

2. Yusuf S, Hawken S, Ounpuu S, et al. INTERHEART Study Investigators effect of potentially modificable risk factors associated with myocardial infarction in 52 countries (the INTERHEART study): case control study. Lancet. 2004;364:937-952.

3. World Health Organization. High blood pressure - country experiences and effective interventions utilized across the European Region. Available at: http://www.euro.who.int/_data/assets/pdf_file/0008/185903/e96816.pdf.

4. World Health Organization. Global Health Observatory (GHO) data: Raised blood pressure. Available at: http://www.who.int/gho/ncd/risk_factors/ blood_pressure_prevalence_text/en.

5. Blumenthal JA, Babyak, MA, Hinderliter, A et al. Effects of the DASH diet alone and in combination with exercise and weight loss on blood pressure and cardiovascular biomarkers in men and women with high blood pressure: the ENCORE study. Arch Intern Med. 2010;170:126.

6. Bacon SL, Sherwood A, Hinderliter A, Blumenthal JA. Effects of exercise, diet and weight loss on high blood pressure. Sports Med. 2004;34:307316

7. Karanja N, Erlinger T, Pao-Hwa L, Miller ER, Bray GA. The DASH diet for high blood pressure: from clinical trial to dinner table. Cleve Clin J Med. 2004;71:745-753.

8. United States Department of Health and Human Services, National Institutes of Health, National Heart Lung, and Blood Institute. Your Guide to Lowering Your Blood Pressure With DASH. NIH Publication. 2006;065834. Available at: https://www.nhlbi.nih.gov/files/docs/public/heart/new_ dash.pdf

9. Lichtenstein $\mathrm{AH}$, Appel $\mathrm{LJ}$, Brands $\mathrm{M}$, et al. Diet and lifestyle recommendations revision 2006. A scientific statement from the American Heart Association nutrition committee. Circulation. 2006;114:82-96.

10. Hyun K, Flavia CD. Diagnostic status of hypertension on the adherence to the Dietary Approaches to Stop Hypertension (DASH) diet. Prev Med Rep. 2016;4:525-531.

11. Fung TT, Chiuve SE, McCullough ML, Rexrode KM, Logroscino G, Hu FB Adherence to a DASH-Style Diet and Risk of Coronary Heart Disease and Stroke in Women. Arch Intern Med. 2008:168:713-720.

12. Karanja NM, Obarzanek E, Lin PH, et al. DASH Collaborative Research Group. Descriptive characteristics of the dietary patterns used in the Dietary Approaches to Stop Hypertension Trial. J Am Diet Assoc. 1999;99:S19-S27.

13. World Health Organization. Waist Circumference and Waist-Hip Ratio: Report of a WHO Expert Consultation, 2008. Available at: http://www.who. int/nutrition/publications/obesity/WHO_report_waistcircumference_and_ waisthip_ratio/en/.

14. World Health Organization. Frequently asked questions about salt in the WHO European Region. 2012. Available at: http://www.euro.who. int/en/what-we-do/healthtopics/disease-prevention/nutrition/news/ news/2011/10/reducing-salt-intake/frequently-askedquestions-about-saltin-the-who-european-region.

15. Centers for Disease Control and Prevention. Application of lower sodium intake recommendations to adults - United States, 1999-2006. Available at: http://www.cdc.gov/mmwr/preview/mmwrhtml/mm5811a2.htm.

16. Schmidhuber J, Traill WB. The changing structure of diets in the European Union in relation to healthy eating guidelines. Public Health Nutrition. 2005:9:584-595.

17. Strazzulo P, D’Elia L, Kandala NB, Cappuccio FP. Salt intake, stroke, and cardiovascular disease: metaanalysis of prospective studies. BMJ. 2009:339:b4567.

18. Hajjar IM, Grim CE, George V, Kotchen TA. Impact of diet on blood pressure and age-related changes in blood pressure in the US population: analysis of NHANES III. Arch Intern Med. 2001;161:589.

19. Obarzanek E, Sacks FM, Vollmer WM, et al. Effects on blood lipids of a blood pressure-lowering diet: the dietary approaches to stop hypertension (DASH) trial. Am J Clin Nutr. 2001;74:80-89.

20. Sacks FM, Svetkey LP, Vollmer WM, et al. Effects on blood pressure of reduced dietary sodium and the dietary approaches to stop hypertension (DASH) diet. N Engl J Med. 2001;344:3-10.

21. Appel LJ, Moore TJ, Obarzanek E, et al. A clinical trial of the effects of dietary patterns on blood pressure. N Engl J Med. 1997;336:1117-1124.

22. Chen ST, Maruthur NM, Appel LJ. The effect of dietary patterns on estimated coronary heart disease risk results from the dietary approaches to stop hypertension (DASH) trial. Circ Cardiovasc Qual Outcomes. 2010;3:484-489.

23. Hu FB, Willett WC. Optimal diets for prevention of coronary heart disease JAMA. 2002;288:2569-2578.

24. National Health and Nutrition Examination Survey: 2009-2012. Prevalence of coronary heart disease by age and sex. Available at: https:// www.heart.org/idc/groups/heartpublic/@wcm/@sop/@smd/documents/ downloadable/ucm_449846.pdf. 